\title{
Iodine in a nutshell: what do you need to know?
}

\author{
Fahad Awwadh Alotaibi
}

University of Ottawa

* Correspondence: falot023@uottawa.ca

\begin{abstract}
When you type" Iodine" in google scholar, you will end up with 2,200,000 articles that are titled with anything regarding iodine, except "what is it". Here in this short note review, a summary of iodine that includes its origin, structure, types, sources, uses, concentration, toxicity, and iodine intake and how to measure it, was collected and infused in a nutshell.
\end{abstract}

Keywords: Iodine; Iodine types; Iodine radioisotope; Iodine 129; Iodine toxicity; iodine intake; Iodine content in Canadian food

\section{General overview of iodine}

Iodine (Fig1) is derived from nucleosynthesis that occurred 10 billion years ago in a star-supernova explosion that dispersed the dust that formed planet Earth (Venturi 2011). It is the second heaviest element to be essential in living organisms (Chauvel 2018). Iodine is a non-metallic, grayish-black element of the halogen group of the periodic system with symbol I (Safranovski, n.d.) and was discovered by French chemist Bernar cartois in 1811 A.D. and named iode from the Greek "ioeides" which means violet because of the color of iodine vapor (Chauvel 2018). Iodine is a minor component on earth (10 ppb for the bulk silicate earth) and is mostly concentrated in oceans and sediments because it is highly soluble. It is found in nature in form of Iodide, iodate, elemental iodine, and organic iodine. (Chauvel 2018). The chemical and physical properties of iodine were summarized in table1.

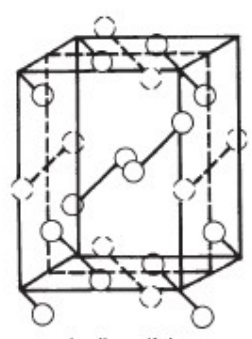

Figure 1. Iodine $\left(I_{2}\right)$ molecular structure adapted from (Hibbert et al. 1987). 
Table 1. Chemical and physical properties of iodine.

\begin{tabular}{cc}
\hline Property & $126.9054 \mathrm{~g} / \mathrm{mol}$ \\
\hline Atomic mass & 53 \\
Atomic number & $184.4 \mathrm{C}$ \\
Boiling point & $4.93 \mathrm{~g} / \mathrm{cm}^{3}$ \\
Density (at 25C) & 37 \\
Isotopes & 113.5 \\
Melting point & $-1,+1,+3,+5,+7$ \\
Oxidation state & $0.34 \mathrm{~g} / \mathrm{L}$ \\
Solubility (at 25C) & $40 \mathrm{~Pa}$ \\
\hline
\end{tabular}

\section{Uses of iodine and its function:}

Iodine is generally used as a local anti-infective agent for skin wounds. Also, as a disinfecting agent in the form of tablets for water treatment or solutions for surfaces in hospitals, surgical tools, and laboratories (Backer and Hollowell 2000). Inside the human body, iodine is required to form thyroid hormones which are important for metabolism and growth (Agency for Toxic Substances and Disease Registry 2004). Also, iodine may play a vital role in protecting protein and DNA molecules in animal cells from oxidation due to the fact that iodide is antioxidant (Venturi 2010). Moreover, it has been found that iodide has a relation to the activity of enzymes that acts as antioxidants such as catalase, glutathione peroxidase, and superoxide dismutase (Soriguer et al. 2011).

\section{Sources of iodine in the environment and the human:}

Iodine occurs naturally in the environment and can be found in all environmental reservoirs including the hydrosphere, biosphere, atmosphere, and geosphere Fig.2. In addition, iodine is a mobile, redox-sensitive element that distributes readily in the environment due to its high affinity for aqueous fluids (Chauvel 2018). Iodine exists in the atmosphere as particulate iodine, organic and inorganic gaseous iodine and its concentration in the atmosphere ranges from $1 \mathrm{ng} / \mathrm{m}^{3}$ to $100 \mathrm{ng} / \mathrm{m}^{3}$. In the hydrosphere, iodine concentration ranges from $1 \mathrm{ng} / \mathrm{ml}$ to $60 \mathrm{ng} / \mathrm{ml}$. In the geosphere, iodine existence is associated to organic matter and its concentration varies based on location. In the biosphere, iodine enters to the body of plants through absorption from the surrounding environment and enters the body of mammals through ingestion (Hou et al. 2009). Most of the iodine in the environment is derived from volatilization from ocean while little is derived from weathering of the lithosphere (Selinus et al. 2013). The geochemical studies of iodine indicate that iodine is volatilized from oceans, carried overland by winds, and deposited on the soil by rain (Van Nostrand's Scientific Encyclopedia). Therefore, desert areas such as Saudi Arabia are expected to be low in iodine.

In terms of the human diet, a significant percentage of iodine daily intake is from food consumption. The human diet is the major source of iodine in the human population. An additional source of iodine may come through taking medications (e.g., amiodarone) or multivitamins. Most of the dietary iodine is absorbed by small intestine and transferred then into blood (Hays 1984). Table 2 summarized the content of iodine in some of the most commonly consumed food in Canada. 


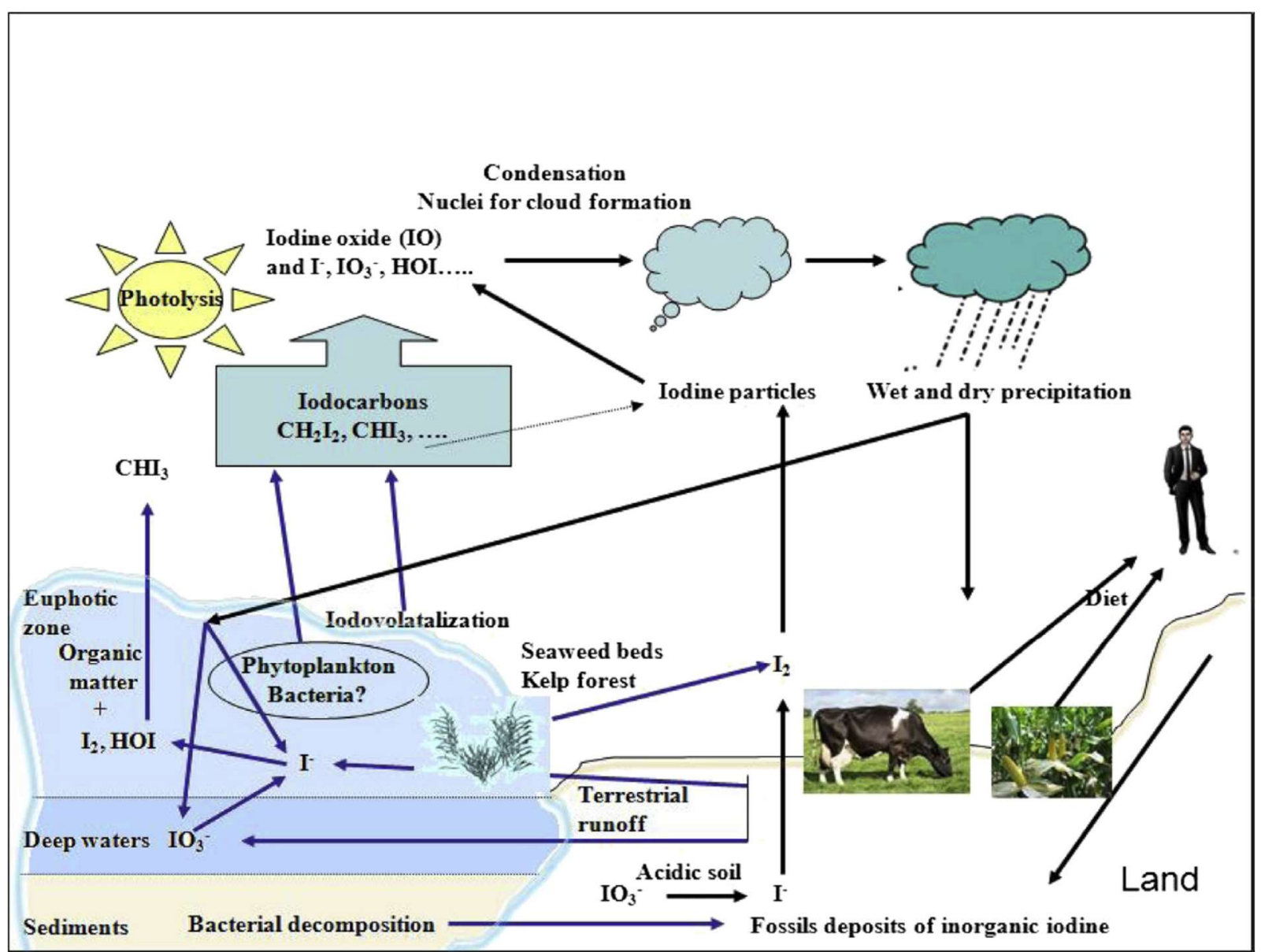

Figure 2. Iodine distribution through different chemical forms in the environment. Source from (Jabbar, Wallner, and Steier 2013).

Table 2. Iodine content in selected Canadian food. Adopted from (Benkhedda et al. 2009).

\begin{tabular}{ccc}
\hline & Food type & Iodine Concentration $\boldsymbol{\mu g} / \boldsymbol{g}$ \\
\hline 1 & Tea, coffee, and water & 0.028 \\
2 & Grain products & 0.164 \\
3 & Fruits and Vegetables & 0.028 \\
4 & Milk & 0.268 \\
& whole & 0.317 \\
& $2 \%$ & 0.301 \\
& $1 \%$ & 0.258 \\
& skimmed & 0.160 \\
5 & raw milk & 0.493 \\
6 & Yoghurt & 0.105 \\
8 & Beef & 0.346 \\
9 & Chicken & 1.163 \\
10 & Cheese & 0.640 \\
11 & Fish & 0.727 \\
\end{tabular}

\section{Isotopes of iodine}

Thirty-seven isotopes of iodine are identified, beginning with ${ }^{108} \mathrm{I}$ up to ${ }^{145}$ I. The only iodine isotope that is stable is ${ }^{127} \mathrm{I}$. All of the other isotopes are radioactive. Iodine isotopes ${ }^{123} \mathrm{I},{ }^{125} \mathrm{I},{ }^{129} \mathrm{I}$, and ${ }^{131} \mathrm{I}$ are interest (Hou and Ding 
2009). The nuclear prosperities and applications of some radioiodine are presented in table 3.

Table 3. Nuclear prosperities and application of some radioiodine, modified from (Coenen, Mertens, and Maziere 2006).

\begin{tabular}{rccc}
\hline & Mode of decay & Half life & Application \\
\hline${ }^{123} \mathrm{I}$ & $\mathrm{EC}$ & 13.2 hours & Nuclear medicine diagnostic tests such as scintigraphy and SPET “single- \\
${ }^{125} \mathrm{I}$ & $\mathrm{EC}$ & 59.4 days & photon emission tomography". \\
${ }^{129} \mathrm{I}$ & $\boldsymbol{\beta}-$ & 16.14 million years & Radioimmunoassay "RIA", and tracer in lab experiments \\
${ }^{131} \mathrm{I}$ & $\boldsymbol{\beta}-$ & 8.02 days & dating tool, oceanography, and groundwater tracer \\
\hline
\end{tabular}

\subsection{Iodine-123}

${ }^{123}$ I is a short-lived radioisotope with a half-life of 13.2 hours (Hupf, Eldridge, and Beaver 1968) and decays by electron capture and emits low energy electron $=0.159 \mathrm{MeV}$ (Narra et al. 1992). It is produced anthropogenically from a nuclear reaction in a cyclotron and there have been about 25 nuclear reactions proposed, the most common one is from Tellurium-123 ${ }^{123} \mathrm{Te}(p, n){ }^{123}$ (COENEN, MERTEN, and MAZIE'RE 2006). Due to its unique short half-life and low energy that decreases the radiation risk, iodine 123 is used mainly in nuclear medicine as a diagnostic tool and imaging. For example, iodine- 123 has been used to study thyroid gland uptake, iodine metabolism in the human body, and imaging studies for the brain (Myers 1973; Narra et al. 1992). Moreover, iodine-123 metaiodobenzylguanidine (123I-MIBG) is considered by many physicians as a non-invasive tool for the diagnosis of ventricular arrhythmias and other cardiovascular risks in cardiac patients (Van Vickle and Thompson 2015; Stefanelli, Treglia, and Giordano 2012).

\subsection{Iodine- 125}

${ }^{125} \mathrm{I}$ is the second short-lived radioisotope discovered by Reid and Keston in 1946 in tellurium solution that bombarded with deuterium (Baker and Gerrard, n.d.). It has a half-life of 59.4 days and decays by electron capture and emits low energy electron $=35.5 \mathrm{KeV}$ (COENEN, MERTEN, and MAZIE 'RE 2006). ${ }^{125} \mathrm{I}$ is produced anthropogenically from the nuclear reaction of Tellurium-125 in cyclotron ${ }^{125} \mathrm{Te}(p, n){ }^{125} \mathrm{I}$ or from reactor irradiation of Xenon-124 (Baker and Gerrard, n.d.). Many scientists prefer the use of ${ }^{225}$ I over ${ }^{131}$ I since the former has a longer half-life with no beta radiation (Narra et al. 1992). These characteristics expand the application of ${ }^{125} \mathrm{I}$ in many fields which are mostly in scientific research and labelling (Paxton, Rowell, and Cree 1978; Baker and Gerrard, n.d.) with serious attempts to use it in cancer therapy that gave promising results (Gutin et al. 1984; Martinez-Monge et al. 1999). In term of medical radiography, ${ }^{125}$ I was used for SPECT imaging but its low energy emissions ( $35.5 \mathrm{KeV})$ makes it only suitable for small animals (Cavina et al. 2017).

\subsection{Iodine- 127}

${ }^{127} \mathrm{I}$ is the stable form of iodine that is an essential element in the formation of thyroid hormones which are important for metabolism and growth in humans and animals (Agency for Toxic Substances and Disease 
Registry 2004). More than $80 \%$ of iodine in the human body resides in the thyroid gland (Hou and Ding 2009). The World Health Organization (WHO) recommends that daily iodine intake should be 90-120 $\mu \mathrm{g}$ for children less than twelve, $150 \mu \mathrm{g}$ for children above twelve and adults, and $250 \mu \mathrm{g}$ for pregnant and lactating women (Agency for Toxic Substances and Disease Registry 2004). If the iodine concentration in the body is below these recommended levels; iodine deficiency occurs (Mannar and Dunn 1995). Iodine deficiency has the most attention in the WHO since 1945 and it is claimed that two billion individuals all over the world have insufficient iodine intake (Zimmermann 2009a). Iodine deficiency is classified into moderate and mild deficiencies, and is linked to many health disorders such as Autism, Hypothyroidism, Brain damage, Psychomotor impairment, and Goitre (table 4). According to the WHO data (Fig 3), 47 countries have iodine deficiency; 10 were classified as moderate iodine deficiency and the remaining 37 were classified as mild (de Benoist et al. 2004). According to the Canadian Health Measures Survey (CHMS) results, the median concentration of iodine in Canada was $151 \mu \mathrm{g} / \mathrm{L}$ which is within the range of optimal intake recommended by the WHO (Statistics Canada 2012).

Table 4. Health disorders linked with IDD.

\begin{tabular}{cc}
\hline Physiological groups & Iodine Deficiency Disorders \\
\hline All Ages & Goitre - Hypothyroidism \\
Adult & Impaired mental function \\
Child and adolescent & Amportion \\
Pregnant woman & Impaired mental function - Delayed physical developent \\
\hline
\end{tabular}




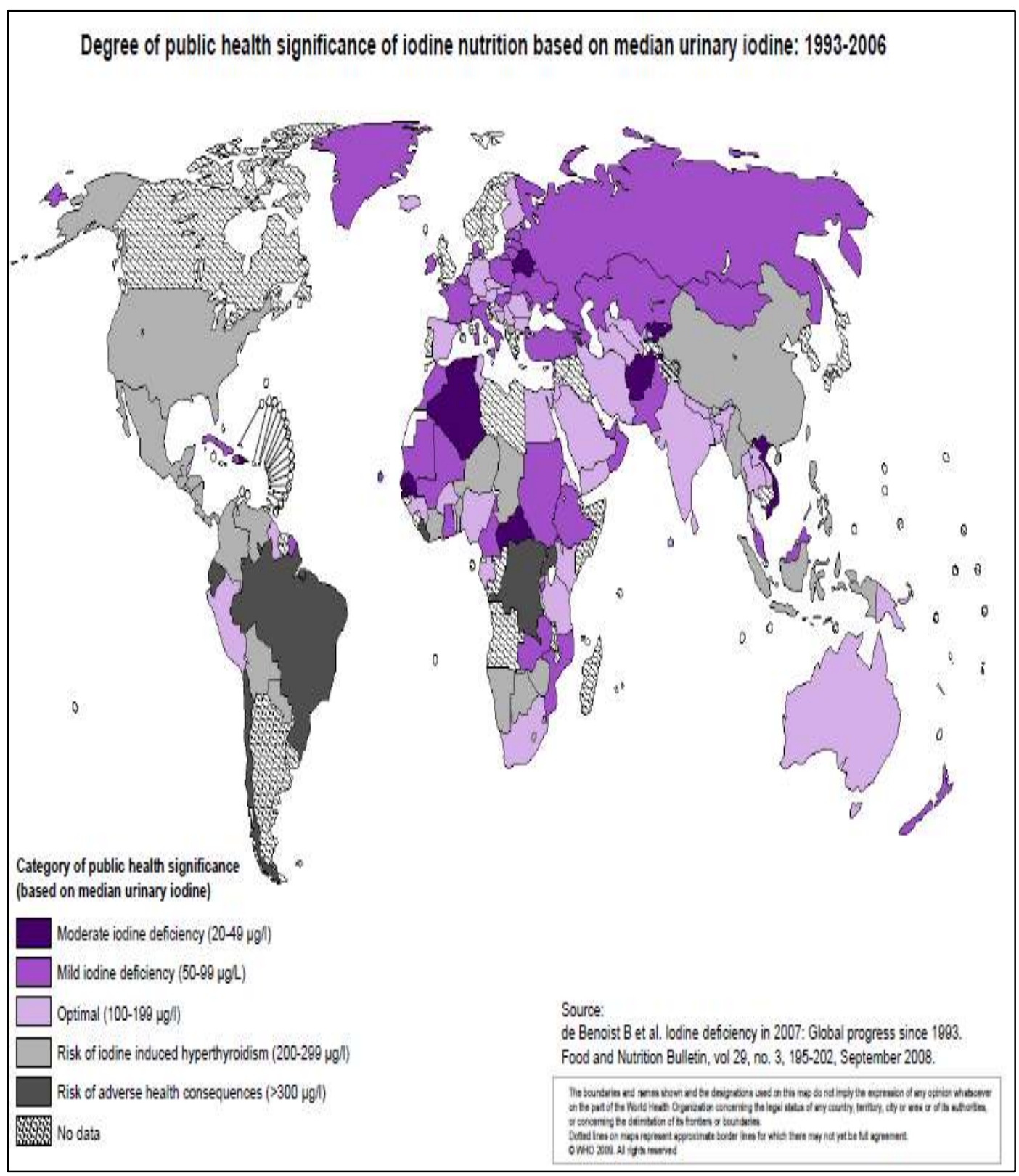

Figure 3. Degree of iodine status worldwide based on urinary iodine concentration.

To combat iodine deficiency, iodine is introduced regularly into the human diet. Many types of food such as salt, milk, bread, and water have been considered as possible transporters(de Benoist et al. 2004). Among these foods, salt was internationally accepted, because it is widely used in culinary recipes. Therefore, it is recommended as a supplement to cure iodine deficiency disorder (IDD) internationally (Mannar and Dunn 1995). As a consequence, many studies suggest that iodized salt is a very important source of iodine in human. For example, (Gunnarsdottir and Dahl 2012) mentioned that iodized table salt is the main dietary source of iodine in the human diet and provides $50 \%$ of iodine intake essentially in Sweden. Other studies (Pandav et al. 2013) \& (Fields and Borak 2009) mentioned the same concept indirectly by saying that avoiding iodized salt may increase the risk 
of iodine deficiency. Moreover, the WHO and the International Council for Control Iodine Deficiency Disorder (ICCIDD) believe that iodine fortification in salt is an important strategy for iodine deficiency elimination (Mannar and Dunn 1995)(de Benoist et al. 2004).

In contrast, (K. E. Charlton et al. 2013) study shows that lower iodized salt intakes do not compromise iodine status at study population in Cape Town, South Africa. In addition, (He et al. 2016) studied the effect of salt reduction on iodine status. Their findings indicate that reducing salt consumption to $30 \%$ is not compromising iodine status. Moreover, (Nazeri et al. 2015) shows that iodine status is inadequate for a lactating woman, although with mandatory salt iodization. This indicates that iodized salt has a minor effect on iodine status. Furthermore, (K. Charlton et al. 2014) were concerned about the WHO recommendation to reduce salt intakes by $30 \%$ in 2025 and tested how far this reduction may compromise iodine status due to the fact that iodized salt is a good strategy to eliminate IDD. Their study concludes that there is no difference in iodine status between women who are salt intakes and women how are non-salt intakes and both groups have a mild iodine deficiency. Therefore, empirical knowledge of iodine sources in the human body is needed. There is a lack of knowledge empirically to identify the most important sources of iodine. In another word, an empirical study that traces the sources of iodine in the human body and its relationship with the human diet is lacking in the iodine area. Most studies consider that high content of iodine in specific food reflects food importance as a source of iodine in the human diet, ignoring many factors such as daily intake, iodine loss during storage or cooking, and iodine absorption and metabolism in presence of iodine inhibitors.

\subsection{Iodine-129:}

${ }^{129} \mathrm{I}$ is a long-lived radioisotope with a half-life of 16.14 million years (García-Toraño et al. 2018). It is produced naturally by the nuclear interaction of cosmic rays with xenon in the upper atmosphere and by the spontaneous fission of uranium-238 in minerals (Raisbeck and Yiou 1999). The natural production of iodine 129 is estimated as $5.29 \times 10^{5} \mathrm{~Bq} / \mathrm{y}$, while the anthropogenic production ranges from $3.7 \times 10^{11}$ to $5.21 \times 10^{11} \mathrm{~Bq} / \mathrm{y}$ (Sunny et al. 2014). Therefore, the $\mathrm{I}^{-129} / \mathrm{I}^{-127}$ ratio in environmental samples ranges from $10^{-12}$ up to $10^{-4}$ (Fig.4) (Zhang and Hou 2013). Since 1945, the concentration of ${ }^{129}$ In the environment has increased sharply due to anthropogenic nuclear activities such as nuclear weapons testing, nuclear fuel reprocessing plants (NFRP), and a minor contribution from nuclear power plant (NPP) accidents and emissions (Fig.5). A study by Zhang et al. 2013 differentiated ${ }^{129} \mathrm{I} /{ }^{127} \mathrm{I}$ ratios into three categories: pre-nuclear era natural levels with ${ }^{129} \mathrm{I} /{ }^{127} \mathrm{I}$ ratios of $10^{-12}$, modern background ${ }^{129} /{ }^{127} \mathrm{I}$ ratios ranging from $10^{-11}$ to $10^{-9}$, and contaminated areas that have ${ }^{129} \mathrm{I} /{ }^{127} \mathrm{I}$ ratios from $10^{-8}$ higher. As a mobile long-lived radioisotope in the hydrosphere and atmosphere, iodine is distributed throughout the environment and can easily enter the food chain through the hydrosphere, atmosphere, and geosphere.(Zhang and Hou 2013; Jabbar, Wallner, and Steier 2013). Since ${ }^{129} \mathrm{I}$ is a fission product, it is a very good indicator of the global dispersion of nuclear emissions, without being itself a dangerous radioisotope. Owing to its characteristics, which are solubility in water, volatility in air, and long-living, iodine is distributed through different chemical forms in the 
environment and can stay in oceans up to $10^{5}$ years and in the atmosphere up to 30 days (Zhang and Hou 2013)(Jabbar, Wallner, and Steier 2013)

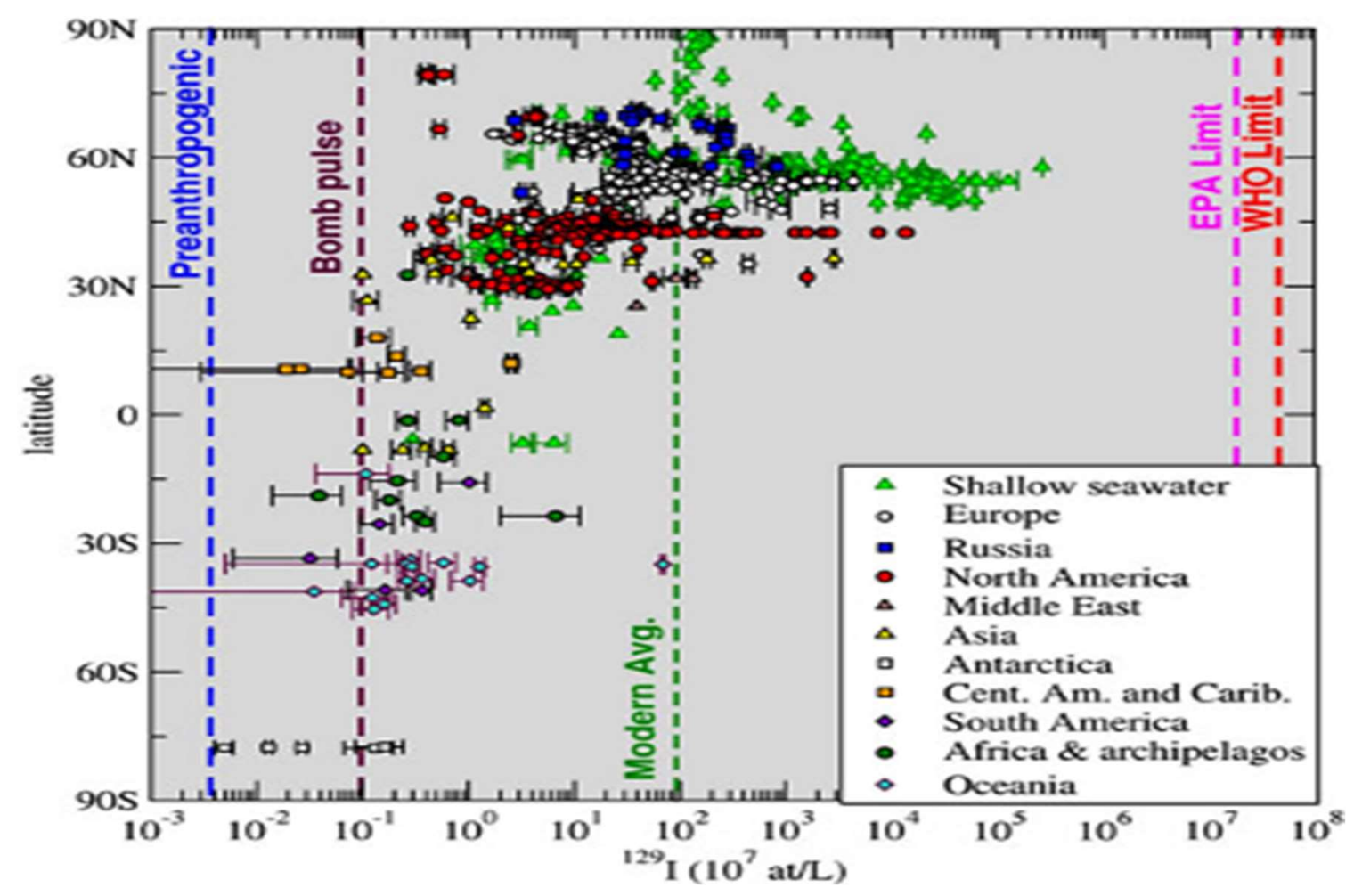

Figure 4. Global distribution of ${ }^{129} /{ }^{127} \mathrm{I}$ ratios in shallow seawater, rivers and lakes. adapted from (Zhang and Hou 2013).

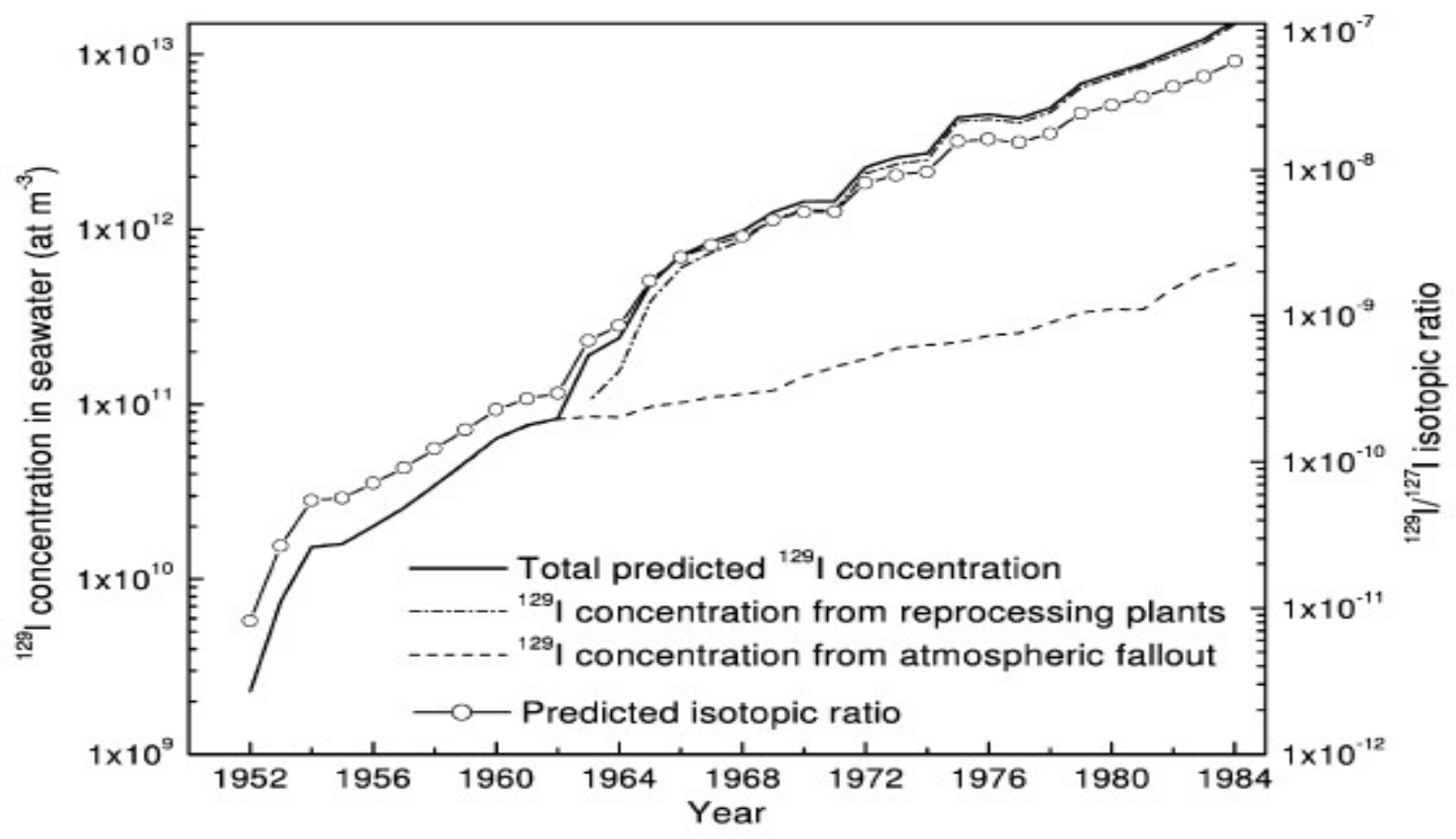


Figure 5. The impact of the reprocessing plants on ${ }^{129} \mathrm{I}$ concentration over time. adapted from (LópezGutiérrez et al. 2004).

Applications of ${ }^{129} \mathrm{I}$ are typically limited to environmental investigations such as its use as a tracer in oceanography, groundwater dating or nuclear emissions (Zhang and Hou 2013; Jabbar, Wallner, and Steier 2013). Due to the sensitivity of AMS, there is an opportunity to expand the use of ${ }^{129} \mathrm{I}$ applications into new fields such as biomedical applications or nutrition. Recently, (Awwadh, Cornett, and Herod 2021) study successfully extracted ${ }^{129}$ I from human urine using hydrogen peroxide as a solvent. The concentration of ${ }^{127} \mathrm{I}$ and ${ }^{129} \mathrm{I}$ in their urine samples were significantly correlated and generally similar to the ${ }^{129} \mathrm{I}$ concentrations and ${ }^{129} \mathrm{I} /{ }^{127} \mathrm{I}$ ratios from environmental samples that are collected around the place of residency. The ability to measure ${ }^{129} \mathrm{I}$ in human urine expands the application of ${ }^{129} \mathrm{I}$ in the biomedical field and its use as a tracer, such as the investigation of the sources of iodine in the human diet and their relative importance for iodine sufficiency or investigations of 131 I uptake in the event of a nuclear emergency using ${ }^{129} \mathrm{I}$ in urine as a proxy. Furthermore, it can help to evaluate ${ }^{129} \mathrm{I}$ exposure directly in the people who live near or downstream from a contaminated area such as nuclear reprocessing plants.

\subsection{Iodine-131}

${ }^{131} \mathrm{I}$ is the most known radioisotope of iodine. It has a half-life of 8.02 days and decays by beta emission giving energy electron $=606 \mathrm{KeV}$ (Mody et al. 2015; Cavina et al. 2017). It is produced as a fission of ${ }^{235} \mathrm{U}$ or anthropogenically from nuclear reaction of Tellurium-130 in cyclotron ${ }^{130} \mathrm{Te}$ $(n, \gamma){ }^{131} I$ (COENEN, MERTEN, and MAZIE RE 2006). ${ }^{131} \mathrm{I}$ is considered as the most dangerous radio fission contaminant of nuclear accidents. It can be found in air, water, soil, and plants, and can enter the human body through inhalation or ingestion (WHO 2017). On one hand, it is well known that thyroid tumors are the common incidences that are observed after nuclear accidents or atomic bombs, and higher rates of thyroid cancer were linked to radioactive iodine ${ }^{131} \mathrm{I}$ after Chernobyl accidents (Likhtarev et al. 1995). On the other hand, ${ }^{131} \mathrm{I}$ is the most common and widely used radioisotope in medical diagnosis and shows notable success in therapeutic purposes, such as radioimmunotherapy for thyroid cancer as well as neuroendocrine tumors and hematologic malignancies (Scott and Lee 2008). Although, ${ }^{131}$ I from external radiation is linked to thyroid cancers, the therapeutic ${ }^{131} \mathrm{I}$ causes fewer cancer cases (Hall, Mattsson, et al. 1996; Hall, Fürst, et al. 1996). For this discrepancy, an excellent explanation was given by (Hindié et al. 2002). It concludes that the thyroid gland is increasingly sensitive to radiation with decreasing age. Children and adolescents are at higher risk of developing radiation-induced thyroid cancer, since their uptake rate is higher during the development, and their tissue dose also is higher due to the small size of their thyroid glands. Therefore, (Hindié et al. 2002) recommended that the medical use of ${ }^{131}$ I should not be performed in children. In addition, it was observed that the toxicity of ${ }^{131} \mathrm{I}$ when entering the organisms through inhalation is higher than ingestion (Luchanskii et al. 1988). Therefore, the route of exposure to ${ }^{131} \mathrm{I}$ could play a significant role in developing radiation-induced thyroid cancer. 


\section{Iodine toxicokinetic to humans:}

\subsection{Absorption:}

The main route of iodine exposure is through ingestion, then inhalation, and very low concentration will be absorbed through skin or eye. (Riggs 1952) reported that $90 \%$ of the radioiodine amount is absorbed in 45 min after digestion and the total amount stays in the body for more than $30 \mathrm{hrs}$. Molecular iodine, inorganic iodine or iodine ingested in forms other than iodide is converted into the iodide ion before it is absorbed (Agency for Toxic Substances and Disease Registry 2004). The absorption rate of iodine in the gastrointestinal tract is reported to be similar in all ages above 18 years old (Sternthal1980). Nonetheless, the presence of perchlorate, thiocyanates, isothiocyanates, and nitrates can decrease iodide absorption which may lead to a decrease in thyroid production. (Prasad et al 2020). The fraction absorbed of iodine in humans was not reported because iodine cannot be administrated by injection; therefore, iodine bioavailability is usually calculated based on dietary iodine where daily iodine intake is a major factor (“1997_Hurrell_Bioavailability_of_iodine_EJCN.Pdf," n.d.)

\subsection{Distribution/ Metabolism}

Once iodine is absorbed into the bloodstream, it must be distributed to its site of action, i.e., the thyroid gland. More than $80 \%$ of the iodine in the human body is stored in the thyroid gland (Hou and Ding 2009). The thyroid gland is an endocrine gland located on the front and sides of the trachea and produces three types of hormones: thyroxine (T4), triiodothyronine (T3), and calcitonin. Iodine is essential to the synthesis of T4 and T3. Thyroxine $\left(\mathrm{C}_{15} \mathrm{H}_{11} \mathrm{O}_{4} \mathrm{I}_{4} \mathrm{~N}\right)$ has four atoms of iodine while triiodothyronine (T3) has three atoms of iodine. Both hormones functioning similarly in the body to synthesis of protein, and to produce energy by increasing cell respiration of carbohydrates, fatty acids, and amino acids molecules. In general, T4 and T3 contribute to the growth of mammals' body parts and organs such as muscles, liver, and brain (Scanlon 2007). In order to adequately synthesize T4 and T3, the thyroid gland requires no more than $70 \mu \mathrm{g}$ daily. The recommended daily allowance level of iodine $150 \mu \mathrm{g} /$ day, which doubles the thyroid gland required value, may be necessary for optimal function of other non-thyroidal tissues. Thus, further research and study of iodine beyond its role in thyroid hormones is needed (Venturi 2011).

\subsection{Excretion}

Iodine that is not stored in the thyroid gland leaves the body, primarily through urine and a small amount through sweat, saliva, and breast milk (Agency for Toxic Substances and Disease Registry 2004) and its concentration is considerably varied among individuals. Around $97 \%$ of iodine is excreted in the urine as iodide, with limited re-absorption in the kidney (Agency for Toxic Substances and Disease Registry 2004). The excretion of iodine through faeces was reported and its concentration was neglected $<0.5 \%$ (Hays 2001). The excretion half-life is varied among individuals and reported between 15.1 -54.6 days with a mean of 31 days. In terms of dietary iodine, (Agency for Toxic Substances and Disease Registry 2004) reported that iodine leaves the body through urine in few weeks to months. 


\section{Iodine intake}

The relationship between the level of iodine consumption and the risk of thyroid disease is frequently shown in nutrition by U-shaped curves, which mean both low and high intakes are associated with an increase in risk (Laurberg et al. 2001). On one hand, it is well known and documented that a low iodine intake is causing hypothyroidism and is strongly associated with many health disorders such as autism, neuropsychological disorders and learning disabilities in human infants, psychomotor impairment, abortions or stillborn in pregnant women, and endemic goitre (Venturi 2011). On the other hand, excess iodine intake is less frequently addressed. In addition to hyperthyroidism, it has been noticed that excess iodine intake is also associated with endemic goitre and hypothyroidism as same as iodine deficiency (Laurberg et al. 2001).

The content of iodine is low in most food sources except for marine origin, and can be affected by the condition of the soil, the condition of weather, or the condition of cooking during the process of the meals (Zimmermann 2009b; Li et al. 2018). For example, in the area where the soils are high in iodine, groundwater is also high in iodine (Considine 1995). In addition, iodine content in milk of cattle that are grazing near coastal areas is higher than milk from cattle that are grazing in mountains (van der Reijden, Zimmermann, and Galetti 2017). Similar observations were noticed in milk during summer versus winter that iodine content in milk during the summer season is less than winter (Rasmussen, Larsen, and Ovesen 2000). Food processing also affects iodine content in food. For instance, heat during cooking of food removes up to $70 \%$ of the iodine in iodized salt and up to $15 \%$ in some vegetables such as celery (Li et al. 2018). Most foods provide an iodine content of between 3 to 75 micrograms per serving which is, in general, is less than the recommended daily intake.

The Dietary Reference Intake (DRI) for iodine includes 4 types of values that are distributed based on age and gender. The first is Estimated Average Requirement (EAR) which is "the average daily iodine intake level estimated to meet the requirement of half the healthy individuals". The second is Recommended Dietary Allowance (RDA) which is "the average daily dietary iodine intake level sufficient to meet the iodine requirement of almost all $(98 \%)$ of healthy individuals". Sitting the Recommended Dietary Allowance RDA value depends on EAR and can be calculated as RDA=EAR +2SD EAR; where SD = standard deviation of estimated average requirement. However, when RDA cannot be determined for specific age of individuals, such as iodine for infants, the adequate intake is used. Adequate Intake (AI) is "the recommended average daily intake level that is assumed to be adequate based on observed or experimentally determined approximations". For example, the RDA of iodine cannot be determined for infants; therefore, AI is used and it reflects the mean of iodine intake that is observed in infants exclusively fed breast milk. The last value is Tolerable Upper Intake Level (UL) and reflects "the highest average daily iodine intake level that is likely to pose no risk of adverse health effects in $98 \%$ of individuals in the general population". The first effect that was observed in iodine excess was an elevation in TSH concentration. Toxicological studies that applied to identify the No-Observed-Adverse-Effect-Level (NOAEL) and Low-ObservedAdverse-Effect-Level (LOAEL) of iodine, helped to determine the UL of 
iodine. The Tolerable Upper Intake Level (UL) of iodine can be calculated by dividing the LOAEL by the uncertainty factor of toxicological studies. Iodine NOAEL was estimated at $1000-1200 \mu \mathrm{g} /$ day, while LOAEL was estimated at $1700 \mu \mathrm{g} /$ day, and the uncertainty factor was 1.5 .

The Tolerable Upper Intake Level (UL) of iodine $=\underline{\text { LOAEL }}=\frac{1700}{1.5}=1133.3 \mu \mathrm{g} / \mathrm{day}$

Tolerable Upper Intake Level (UL) of iodine for adults was rounded to $1100 \mu \mathrm{g} /$ day, and from this value, the UL for children was calculated and adjusted based on body weight. The values of all four (DRIs) for iodine were summarized in table 5 (Otten, Hellwig, and Linda 2006)

Table 5. The Dietary Reference Intake (DRI) for iodine (Otten, Hellwig, and Linda 2006).

\begin{tabular}{|c|c|c|c|c|}
\hline & EAR $\mu \mathrm{g} /$ day & RDA $\mu \mathrm{g} / \mathrm{day}$ & AI $\mu g /$ day & $\mathrm{UL} \mu \mathrm{g} / \mathrm{day}$ \\
\hline \multicolumn{5}{|l|}{ Infant } \\
\hline $0-6$ & Not possible & Not possible & 110 & Not possible \\
\hline $7-12$ & & & 130 & \\
\hline $1-3$ & 65 & 90 & & 200 \\
\hline $4-8$ & 65 & 90 & & 300 \\
\hline $9-13$ & 73 & 120 & & 600 \\
\hline $19>70$ & 95 & 150 & & 1100 \\
\hline \multicolumn{5}{|l|}{ Pregnancy } \\
\hline $14-50$ & 160 & 220 & & 1100 unless age $<18$, then 900 \\
\hline \multicolumn{5}{|l|}{ Lactation } \\
\hline $14-50$ & 209 & 290 & & 1100 unless age $<18$, then 900 \\
\hline
\end{tabular}

\section{Iodine measurement in human}

Inadequate iodine intake results in inadequate production of thyroid hormones, leading to numerous adverse effects known as iodine deficiency disorders (IDD). Thus, iodine deficiency means the deficiency in the intake and not the deficiency in the body (Al 2007). The current and valid way to estimate iodine intake is through urine samples analysis. The main procedures in which urine can be collected for iodine measurement are either 24-hour urine collection, named urinary iodine estimation (UIE) and expressed as $\mu \mathrm{g} / 24 \mathrm{hr}$ or a spot urinary sample, named urinary iodine concentration (UIC) and expressed as $\mu \mathrm{g} / \mathrm{L}$ (JOLIN and ESCOBARDELREY 1965; Vejbjerg et al. 2009; König et al. 2011). The 24-hour urine collection is considered as a reference standard to determine iodine intake in an individual while the spot urine collection is recommended in populationbased research of iodine intake because 24-hour urine collection is hard to obtain (Vejbjerg et al. 2009). Urine production varies during 24 hours, and it is estimated that the mean urine production for healthy individuals is $83 \mathrm{ml}$ urine per hour during the day and $48 \mathrm{ml}$ per hour during the night (Huang Foen Chung and van Mastrigt 2009) giving a 1.6 L as a mean total urine volume per 24 hours. Therefore, UIE ( $\mu$ g/day) can be calculated by multiplying the UIC of the samples $(\mu \mathrm{g} / \mathrm{L})$ by the volume of the 
corresponding 24-h urine excretion (Andersen et al. 2001; Vejbjerg et al. 2009)(Laurberg et al. 2001).

\section{Conclusion:}

Thirty-seven isotopes of iodine are identified, beginning with ${ }^{108 I}$ up to ${ }^{145} \mathrm{I}$. The only iodine isotope that is stable is ${ }^{127} \mathrm{I}$. This stable iodine was discovered in 1811 and was named after a Greek word means violet. It proved to be an essential element in the formation of thyroid hormones which are important for metabolism and growth in humans and animals. Although the main route of iodine in the human body is through ingestion of food, the iodine content of most foods is low. Therefore, to combat iodine deficiency, the international strategies introduced iodine regularly into the human diet by fortifying common food with iodine. In addition to its importance in the human body, iodine is used in the form of solutions as a local antiseptic for skin or as a disinfectant for surfaces. Iodine radio-isotopes ${ }^{123}$ I, ${ }^{125}$ I, ${ }^{129} \mathrm{I}$, and ${ }^{131}$ I are interest and have been used in many fields such as medical diagnosis, environmental tracing, and therapy.

\section{References}

"1997_Hurrell_Bioavailability_of_iodine_EJCN.Pdf." n.d.

Agency for Toxic Substances and Disease Registry. 2004. “Toxicological Profile for Iodine," no. April: 253.

Al, Wijaya-erhardt E T. 2007. "Efficacy of Daily and Weekly Multiple Micronutrient Food-like Tablets for the Correction of Iodine Deficiency in Indonesian Males Aged" 1980 (3): 137-43.

Andersen, Stig, Klaus Michael Pedersen, Inge Bülow Pedersen, and Peter Laurberg. 2001. “Variations in Urinary Iodine Excretion and Thyroid Function. A 1-Year Study in Healthy Men." European Journal of Endocrinology 144 (5): $461-$ 65. https://doi.org/10.1530/eje.0.1440461.

Awwadh, Fahad, R Jack Cornett, and Matthew N Herod. 2021. "Rapid and Efficient Autoclave Digestion for the Extraction of Iodine-129 from Urine Samples." Journal of Environmental Radioactivity 228 (December 2020): 106528. https://doi.org/10.1016/j.jenvrad.2020.106528.

Backer, Howard, and Joe Hollowell. 2000. "Use of Iodine for Water Disinfection: Iodine Toxicity and Maximum Recommended Dose." Environmental Health Perspectives 108 (8): 679-84. https://doi.org/10.1289/ehp.00108679.

Baker, P S, and Martha Gerrard. n.d. IODINE-125 R3463.

Benkhedda, Karima, André Robichaud, Stéphane Turcotte, Franca J. Béraldin, and Kevin A. Cockell. 2009. "Determination of Total Iodine in Food Samples Using Inductively Coupled Plasma-Mass Spectrometry." Journal of AOAC International 92 (6): 1720-27. https://doi.org/10.1093/jaoac/92.6.1720.

Benoist, Bruno de, Maria Andersson, Ines Egli, Bahi Takkouche, and Henrietta Allen. 2004. "Iodine Status Worldwide." WHO Global Database on Iodine Deficiency. Geneca: World Health Organization, 1-12.

Cavina, Lorenzo, Dion van der Born, Peter H.M. Klaren, Martin C. Feiters, Otto C. Boerman, and Floris P.J.T. Rutjes. 2017. "Design of Radioiodinated Pharmaceuticals: Structural Features Affecting Metabolic Stability towards in Vivo Deiodination." European Journal of Organic Chemistry 2017 (24): 3387-3414. https://doi.org/10.1002/ejoc.201601638.

Charlton, Karen E., Pieter L. Jooste, Krisela Steyn, Naomi S. Levitt, and Abhijeet Ghosh. 2013. “A Lowered Salt Intake Does Not Compromise Iodine Status in Cape Town, South Africa, Where Salt Iodization Is Mandatory." Nutrition 29 (4): 630-34. https://doi.org/10.1016/j.nut.2012.09.010.

Charlton, Karen, Mary Anne Land, Gary Ma, Heather Yeatman, and Fiona Houweling. 2014. "Iodine Status Similarly Suboptimal in Australian Women Who Have Desirable Salt Intakes Compared to Those with Excessive Intakes." Nutrition 30 (2): 234-35. https://doi.org/10.1016/j.nut.2013.05.009.

Chauvel, Catherine. 2018. Incompatible Elements. https://doi.org/10.1007/978-3-319-39312-4_231.

COENEN, HEINZ H., JOHN MERTEN, and BERNARD MAZIE'RE. 2006. RADIOIONIDATION REACTIONS FOR RADIOPHARMACEUTICALS.

Considine, Doughals M. 1995. Van Nostrand's Scientific Encyclopedia. SPRINGER SCIENCE. https://doi.org/10.1017/CBO9781107415324.004.

Fields, Cheryl, and Jonathan Borak. 2009. "Iodine Deficiency in Vegetarian and Vegan Diets: Evidence-Based Review of the World's Literature on Iodine Content in Vegetarian Diets." Comprehensive Handbook of Iodine, 521-31. 
https://doi.org/10.1016/B978-0-12-374135-6.00054-6.

García-Toraño, Eduardo, Timotheos Altzitzoglou, Pavel Auerbach, Marie Martine Bé, Christophe Bobin, Philippe Cassette, Frédéric Chartier, et al. 2018. “The Half-Life of 129I.” Applied Radiation and Isotopes 140 (June): $157-62$. https://doi.org/10.1016/j.apradiso.2018.06.007.

Gunnarsdottir, Ingibjörg, and Lisbeth Dahl. 2012. “Iodine Intake in Human Nutrition: A Systematic Literature Review.” Food E Nutrition Research 56 (1): 19731. https://doi.org/10.3402/fnr.v56i0.19731.

Gutin, P. H., T. L. Phillips, W. M. Wara, S. A. Leibel, Y. Hosobuchi, V. A. Levin, K. A. Weaver, and S. Lamb. 1984. "Brachytherapy of Recurrent Malignant Brain Tumors with Removable High-Activity Iodine-125 Sources." Journal of Neurosurgery 60 (1): 61-68. https://doi.org/10.3171/jns.1984.60.1.0061.

Hall, Per, Carl Johan Fürst, Anders Mattsson, Lars-erik Holm, John D Boice, Peter D Inskip, Per Hall, et al. 1996. “Thyroid Nodularity after Diagnostic Administration of Iodine-131 REFERENCES Linked References Are Available on JSTOR for This Article : You May Need to Log in to JSTOR to Access the Linked References. Thyroid Nodularity after Diagnostic Administration Of" 146 (6): 673-82.

Hall, Per, Anders Mattsson, John D Boide, No Jan, Per Hall, Anders Mattssont, and John D Boice. 1996. “Thyroid Cancer after Diagnostic Administration of Iodine-131 Linked References Are Available on JSTOR for This Article: Thyroid Cancer after Diagnostic Administration of Iodine-131 "' 145 (1): 86-92.

Hays, Marguerite T. 1984. “Compartmental Models for Human Iodine Metabolism.” Mathematical Biosciences 72 (2): 317-35. https://doi.org/10.1016/0025-5564(84)90115-9.

Hays, Marguerite T. 2001. “Normal Young Men” 11 (7): 0-4.

He, Feng J, Yuan Ma, Xiangxian Feng, Wanqi Zhang, Laixiang Lin, Xiaohui Guo, Jing Zhang, Wenyi Niu, Yangfeng $\mathrm{Wu}$, and Graham A MacGregor. 2016. “Effect of Salt Reduction on Iodine Status Assessed by 24 Hour Urinary Iodine Excretion in Children and Their Families in Northern China: A Substudy of a Cluster Randomised Controlled Trial." BMJ Open 6 (9): e011168. https://doi.org/10.1136/bmjopen-2016-011168.

Hibbert, D. B., A. M. James, D. B. Hibbert, and A. M. James. 1987. "Macmillan Dictionary of Chemistry." Macmillan Dictionary of Chemistry, 1-524. https://doi.org/10.1007/978-1-349-18817-8_1.

Hindié, Elif, Laurence Leenhardt, Françoise Vitaux, Nicole Colas-Linhart, Pascale Grosclaude, Pierre Galle, André Aurengo, and B. Bok. 2002. "Non-Medical Exposure to Radioiodines and Thyroid Cancer." European Journal of Nuclear Medicine 29 (SUPPL. 2). https://doi.org/10.1007/s00259-002-0912-4.

Hou, Xiaolin, and Wenjun Ding. 2009. Isotopes of Iodine in Thyroid and Urine: Source, Application, Level and Determination. Comprehensive Handbook of Iodine. Elsevier Inc. https://doi.org/10.1016/B978-0-12-374135-6.00046-7.

Hou, Xiaolin, Violeta Hansen, Ala Aldahan, Göran Possnert, Ole Christian Lind, and Galina Lujaniene. 2009. “A Review on Speciation of Iodine-129 in the Environmental and Biological Samples." Analytica Chimica Acta 632 (2): 181-96. https://doi.org/10.1016/j.aca.2008.11.013.

Huang Foen Chung, John W.N.C., and Ron van Mastrigt. 2009. “Age and Volume Dependent Normal Frequency Volume Charts for Healthy Males." Journal of Urology 182 (1): 210-14. https://doi.org/10.1016/j.juro.2009.02.113.

Hupf, H. B., J. S. Eldridge, and J. E. Beaver. 1968. "Production of Iodine-123 for Medical Applications." The International Journal Of Applied Radiation And Isotopes 19 (4): 345-51. https://doi.org/10.1016/0020-708x(68)90178-6.

Jabbar, Tania, Gabriele Wallner, and Peter Steier. 2013. "A Review on 129I Analysis in Air." Journal of Environmental Radioactivity 126: 45-54. https://doi.org/10.1016/j.jenvrad.2013.07.013.

JOLIN, T., and F. ESCOBARDELREY. 1965. "Evaluation of Iodine/Creatinine Ratios of Casual Samples As Indices Of." The Journal of Clinical Endocrinology and Metabolism 25 (November): 540-42. https://doi.org/10.1210/jcem-25-4-540.

König, Franziska, Maria Andersson, Karin Hotz, Isabelle Aeberli, and Michael B. Zimmermann. 2011. “Ten Repeat Collections for Urinary Iodine from Spot Samples or 24-Hour Samples Are Needed to Reliably Estimate Individual Iodine Status in Women." Journal of Nutrition 141 (11): 2049-54. https://doi.org/10.3945/jn.111.144071.

Laurberg, P, N Knudsen, L Ovesen, and S Andersen. 2001. “Nonmalignant Thyroid Disease” 11 (5).

Li, Rui, De Wang Li, Ai Lan Yan, Chun Lai Hong, Hui Ping Liu, Le Hua Pan, Ming Yi Song, Zhi Xi Dai, Ming Li Ye, and Huan Xin Weng. 2018. "The Bioaccessibility of Iodine in the Biofortified Vegetables throughout Cooking and Simulated Digestion." Journal of Food Science and Technology 55 (1): 366-75. https://doi.org/10.1007/s13197-0172946-4.

Likhtarev, I. A., B. G. Sobolev, I. A. Kairo, N. D. Tronko, T. I. Bogdanova, V. A. Oleinic, E. V. Epshtein, and V. Beral. 1995. "Thyroid Cancer in the Ukraine." Nature 375 (6530): 365. https://doi.org/10.1038/375365a0.

López-Gutiérrez, J. M., M. García-León, Ch Schnabel, M. Suter, H. A. Synal, S. Szidat, and R. García-Tenorio. 2004. "Relative Influence of 129I Sources in a Sediment Core from the Kattegat Area." Science of the Total Environment 323 (1-3): 195-210. https://doi.org/10.1016/j.scitotenv.2003.09.025.

Luchanskii, A E, S S Martynov, V S Khrunov, and V A Chekhlaev. 1988. “9 1988 Plenum Publishing Corporation 641” 63 (2): 134-35. 
Mannar, Venkatesh M.G., and John T. Dunn. 1995. Salt Iodization for the Elimination of Iodine Deficiency.

Martinez-Monge, Rafael, Subir Nag, Carol A. Nieroda, and Edward W. Martin. 1999. “Iodine-125 Brachytherapy in the Treatment of Colorectal Adenocarcinoma Metastatic to the Liver." Cancer 85 (6): 1218-25. https://doi.org/10.1002/(SICI)1097-0142(19990315)85:6<1218::AID-CNCR2>3.0.CO;2-F.

Mody, Vicky V., Ajay N. Singh, Rahul Deshmukh, and Samit Shah. 2015. Thyroid Hormones, Iodine and Iodides, and Antithyroid Drugs. Side Effects of Drugs Annual. 1st ed. Vol. 37. Elsevier B.V. https://doi.org/10.1016/bs.seda.2015.08.007.

Myers, W.G. et al. 1973. "RADIOIODINE-123 FOR APPLICATIONS IN DIAGNOSIS."

Narra, V. R., R. W. Howell, R. S. Harapanhalli, K. S.R. Sastry, and D. V. Rao. 1992. "Radiotoxicity of Some Iodine-123, Iodine-125 and Iodine-131-Labeled Compounds in Mouse Testes: Implications for Radiopharmaceutical Design." Journal of Nuclear Medicine 33 (12): 2196-2201.

Nazeri, Pantea, Parvin Mirmiran, Niloofar Shiva, Yadollah Mehrabi, Mehdi Mojarrad, and Fereidoun Azizi. 2015. "Iodine Nutrition Status in Lactating Mothers Residing in Countries with Mandatory and Voluntary Iodine Fortification Programs: An Updated Systematic Review." Thyroid 25 (6): 611-20. https://doi.org/10.1089/thy.2014.0491.

Otten, Jennifer J, Jennifer Pitzi Hellwig, and D Linda. 2006. Dietary DRI Reference Intakes. https://doi.org/10.17226/11537.

Pandav, C S, K Yadav, R Srivastava, R Pandav, and M G Karmarkar. 2013. “Iodine Deficiency Disorders (IDD) Control in India." Indian Journal of Medical Research 138 (SEP): 418-33. http://www.scopus.com/inward/record.url?eid=2s2.0-84885073178\&partnerID=40\&md5=ad167a344b5401bf05ac4baa3538fe24.

Paxton, J. W., F. J. Rowell, and G. M. Cree. 1978. “Comparison of Three Radioligands, Selenium-75, Iodine-125, and Tritium, in the Radioimmunoassay of Methotrexate." Clinical Chemistry 24 (9): 1534-38. https://doi.org/10.1093/clinchem/24.9.1534.

Raisbeck, G. M., and F. Yiou. 1999. "129I in the Oceans: Origins and Applications.” Science of the Total Environment 237238: 31-41. https://doi.org/10.1016/S0048-9697(99)00122-9.

Rasmussen, L. B., E. H. Larsen, and L. Ovesen. 2000. "Iodine Content in Drinking Water and Other Beverages in Denmark." European Journal of Clinical Nutrition 54 (1): 57-60. https://doi.org/10.1038/sj.ejcn.1600893.

Reijden, Olivia L. van der, Michael B. Zimmermann, and Valeria Galetti. 2017. "Iodine in Dairy Milk: Sources, Concentrations and Importance to Human Health." Best Practice and Research: Clinical Endocrinology and Metabolism 31 (4): 385-95. https://doi.org/10.1016/j.beem.2017.10.004.

Riggs, Douglas. 1952. "Quantitative Aspects of Iodine in Metabolism in Man."

Scanlon, Valerie. 2007. Essential of Anatomy and Physiology.

Scott, Andrew M., and Sze Ting Lee. 2008. "Clinical Radionuclide Therapy." Targeted Radionuclide Tumor Therapy: Biological Aspects, 349-85. https://doi.org/10.1007/978-1-4020-8696-0_20.

Statistics Canada. 2012. "Health Fact Sheet Body Composition of Canadian Adults, 2009 to 2011," no. 82.

Stefanelli, Antonella, Giorgio Treglia, and Alessandro Giordano. 2012. " 123 I-MIBG Scintigraphy as a Powerful Tool to Plan an Implantable Cardioverter Defibrillator and to Assess Cardiac Resynchronization Therapy in Heart Failure Patients ." International Journal of Molecular Imaging 2012: 1-6. https://doi.org/10.1155/2012/690468.

Sunny, Faby, R. N. Nair, Manish Chopra, and V. D. Puranik. 2014. "Global Environmental Transfer of 129I." Annals of Nuclear Energy 65: 320-24. https://doi.org/10.1016/j.anucene.2013.11.036.

Vejbjerg, Pernille, Nils Knudsen, Hans Perrild, Peter Laurberg, and Stig Andersen. 2009. “Estimation of Iodine Intake from Various Urinary Iodine" 19 (11).

Vickle, S. Seth Van, and Randall C. Thompson. 2015. “123I-MIBG Imaging: Patient Preparation and Technologist's Role." Journal of Nuclear Medicine Technology 43 (2): 82-86. https://doi.org/10.2967/jnmt.115.158394.

WHO. $2017 . \quad$ "Iodine Thyroid Blocking." Who. http://www.iccidd.org/cm_data/2011_Emder_IINH_secondary_to_maternal_seaweed_consumption_JPCH.pdf.

Zhang, Luyuan Y., and Xiaolin L. Hou. 2013. "Speciation Analysis of 129 I and Its Applications in Environmental Research." Radiochimica Acta 540 (July): 130729000243004. https://doi.org/10.1524/ract.2013.2077.

Zimmermann, Michael B. 2009a. “Iodine Deficiency." Endocrine Reviews 30 (4): 376-408. https://doi.org/10.1210/er.20090011. 